PEREIRA JUNIOR, G. et al. Digestibilidade aparente de ração para tambaqui com níveis crescentes de substituição do milho por farinha de crueira de mandioca. PUBVET, Londrina, V. 8, N. 14, Ed. 263, Art. 1751, Julho, 2014.

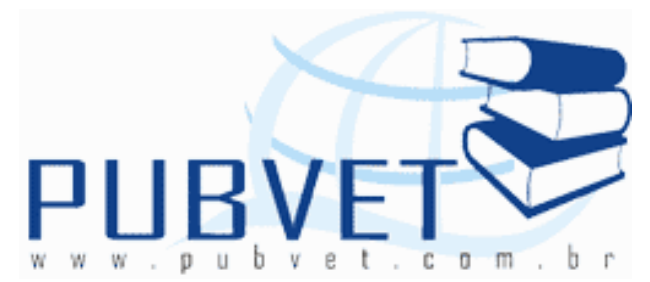

PUBVET, Publicações em Medicina Veterinária e Zootecnia.

\title{
Digestibilidade aparente de ração para tambaqui com níveis crescentes de substituição do milho por farinha de crueira de mandioca
}

\section{Geraldo Pereira junior ${ }^{1}$, Expedita Maria de Oliveira Pereira ${ }^{2}$, Manoel Pereira Filho $^{3}$, Paula de Sousa Barbosa ${ }^{4}$, Fábio Silva de Souza ${ }^{5}$}

${ }^{1}$ Professor do Instituto Federal Fluminense de Ciência e Tecnologia - IFF E-mail: geraldoinpa@hotmail.com

${ }^{2}$ Professora da Universidade Federal do Amazonas - UFAM

E-mail: expeditapzoo@aol.com

${ }^{3}$ Pesquisador do Instituto Nacional de Pesquisas da Amazônia - INPA

E-mail: pmanoel@inpa.gov.br

${ }^{4}$ Aluna de doutorado do Instituto nacional de Pesquisas da Amazônia - INPA

E-mail: manatee_psbd@hotmail.com

${ }^{5}$ Professor da Escola Superior Batista do Amazonas. Medicina Veterinária E-mail: mvfabiosouza@gmail.com

\section{Resumo}

O experimento foi conduzido com o objetivo de avaliar o coeficiente de digestibilidade aparente dos nutrientes de rações para juvenis de tambaqui com níveis crescentes de substituição do milho pela farinha de crueira de mandioca. Foram utilizados 336 juvenis de tambaqui com peso médio de 34,5 $\pm 6,5$. O delineamento experimental foi inteiramente casualizado com seis tratamentos e quatro repetições, perfazendo 24 unidades experimentais. As rações foram formuladas de modo a serem isoprotéicas ( $36 \%$ PB) e 
PEREIRA JUNIOR, G. et al. Digestibilidade aparente de ração para tambaqui com níveis crescentes de substituição do milho por farinha de crueira de mandioca. PUBVET, Londrina, V. 8, N. 14, Ed. 263, Art. 1751, Julho, 2014.

isocalóricas (3500 kcal ED/kg), com níveis crescentes de substituição $(0,20$, 40, 60, 80 e 100\%) do milho pela farinha de crueira de mandioca, correspondendo aos tratamentos controle, I, II, III, IV e V, respectivamente. Os peixes foram alimentados diariamente nos horários de 9:00, 13:00 e 17:30 horas, sendo as fezes coletadas por decantação na coluna da água em intervalos de uma hora. A determinação do coeficiente de digestibilidade aparente (CDA) foi realizada pelo método indireto, sendo utilizado como marcador externo $0,5 \%$ de óxido de cromo $\left(\mathrm{Cr}_{2} \mathrm{O}_{3}\right)$ incorporados às rações. Os resultados demonstraram que a substituição total do milho pela farinha de crueira de mandioca em rações para juvenis de tambaqui não compromete a digestibilidade aparente dos nutrientes.

Palavras-chave: peixe, carboidrato, fezes, nutrição.

\title{
Apparent digestibility of diets for tambaqui with increasing levels of substitution of corn by cassava flour crueira
}

\begin{abstract}
This experiment was lead with the aim to evaluate the apparent digestibility of the ration nutrients for young tambaqui, with growing levels of corn substitution for the manioc flour. There were been used 336 tambaqui with $34,5 \pm 6,5 \mathrm{~g}$ medium weight. The experimental limitation was entirely combined with six treatment and four repetitions, resulting in 24 experimental unities. The ration were formulated in way that they could be iso-protein ( $36 \%$ PB) and iso-caloric (3500 kcal ED $/ \mathrm{kg})$, with growing substitution levels $(0,20$, $40,60,80$ e $100 \%$ ) from corn to manioc flour, corresponding to control treatments I, II, III, IV e $V$ respectively. Fishes were daily fed at 9 am, 1 pm and 5:30 pm, and the excrements were collected by decantation in the water column in one hour breaks. The apparent digestibility coefficient (ADC) determination was made by indirect method, being used as external marker $0,5 \%$ of chrome oxide $\left(\mathrm{Cr}_{2} \mathrm{O}_{3}\right)$ incorporated to the rations. The results have
\end{abstract}


PEREIRA JUNIOR, G. et al. Digestibilidade aparente de ração para tambaqui com níveis crescentes de substituição do milho por farinha de crueira de mandioca. PUBVET, Londrina, V. 8, N. 14, Ed. 263, Art. 1751, Julho, 2014.

demonstrated that total substitution of corn by manioc flour in young tambaqui rations does not compromise the nutrients apparent digestibility.

Keywords: fish, carbohydrate, feces, nutrition.

\section{INTRODUÇÃO}

O Brasil apresenta enorme potencial para o desenvolvimento da piscicultura, sendo a atividade zootécnica com maior perspectiva de crescimento para as próximas décadas. Diversos são os fatores que apontam para esta realidade, a exemplo das condições edafoclimáticas, produção e produtividade de grãos, quantidade e qualidade de recursos hídricos disponíveis (ARBELAEZ-ROJAS et al., 2002) e número de espécies nativas com potencial para cultivo (VAL, 1995).

Uma espécie que tem se destacado na piscicultura nacional é o tambaqui (Colossoma macropomum), que apresenta boa adaptação ao cativeiro e possui alto valor comercial (CHENG et al., 2003), sendo a espécie nativa mais cultivada atualmente (RUFINO, 2002). Diversas são as características favoráveis ao cultivo do tambaqui, a exemplo da disponibilidade de juvenis para comercialização durante o ano todo (ROLIM, 1995), hábito alimentar diversificado (SILVA et al., 1991), rápido crescimento, boa conversão alimentar (VAL et al., 1998), resistência a baixos níveis de oxigênio dissolvido na água (GRAEF, 1995) e boa aceitação pelos consumidores (HANCZ, 1993). Mas o grande destaque desta espécie para a piscicultura é a boa aceitação a alimentos artificiais (SILVA et al., 1991).

Os custos com alimentação são relativamente altos em cultivos comerciais de peixes, representando o maior percentual dos custos operacionais (PEREIRA FILHO, 1995). Por este motivo, é necessário baratear os custos de produção das rações para tornar a piscicultura uma atividade comercial mais atrativa (SILVA et al., 2007). Uma alternativa que tem contribuído para isso é a substituição total ou parcial dos ingredientes comumente utilizados em rações 
PEREIRA JUNIOR, G. et al. Digestibilidade aparente de ração para tambaqui com níveis crescentes de substituição do milho por farinha de crueira de mandioca. PUBVET, Londrina, V. 8, N. 14, Ed. 263, Art. 1751, Julho, 2014.

para peixes por ingredientes alternativos mais baratos (GALDIOLI et al., 2002; LOPES et al., 2010; LEMOS et al., 2011; PIMENTA et al., 2011).

Para que os peixes apresentem bons resultados produtivos, é necessário que a ração ofertada contenha todos os nutrientes necessários para o bom desempenho (PEREIRA FILHO, 1995). Também é importante que os nutrientes da ração sejam bem aproveitados pela espécie cultivada (PEZZATO et al., 2009). Neste sentido, a determinação dos coeficientes de digestibilidade tem sido instrumento de grande importância na área da nutrição de peixes, uma vez que é possível avaliar a capacidade de determinada espécie utilizar os nutrientes da ração (ABMORAD; CARNEIRO, 2004). Isso tem viabilizado o uso de vários subprodutos da agroindústria em rações balanceadas para peixes (PEZZATO et al., 2002; MEURER et al., 2003; OLIVEIRA-FILHO; FRACALOSSI, 2006; ONO et al., 2008; GUIMARÃES et al., 2011).

Dentre os subprodutos com potencial de utilização em rações para animais, destacam-se os derivados da mandioca (Manihot esculenta), a exemplo da crueira. Este subproduto é obtido na fabricação de farinha da raiz de mandioca, durante a etapa de peneiramento da massa. Por ser composta de entrecascas, fiapos e cepas, a crueira de mandioca possui diâmetro maior do que a malha da peneira, ficando retida durante o peneiramento (TAGLIARI, 1996). Apesar de não existirem dados absolutos a respeito da quantidade produzida deste resíduo, estima-se que $10 \%$ da mandioca utilizada na fabricação de farinha é eliminada na forma de crueira (CEREDA, 1994).

Análises centesimais demonstraram que a crueira, assim como outros subprodutos da farinha de mandioca, possui grande quantidade de carboidrato $(93,7 \%)$ e baixa quantidade de proteína bruta $(1,7 \%)$, sendo um alimento energético com potencial de utilização em rações para animais (LACERDA et al., 2005). Estudos de digestibilidade demonstraram a possibilidade de utilização dos subprodutos da farinha de mandioca em rações para ruminantes (RAMOS et al., 2000; MENEZES et al., 2004; ABRAHÃO et al., 2006) e monogástricos (CAVALCANTE et al., 2005; NASCIMENTO et al., 2005; SILVA et 
PEREIRA JUNIOR, G. et al. Digestibilidade aparente de ração para tambaqui com níveis crescentes de substituição do milho por farinha de crueira de mandioca. PUBVET, Londrina, V. 8, N. 14, Ed. 263, Art. 1751, Julho, 2014.

al., 2008). Entretanto, poucos são os trabalhos que avaliaram a digestibilidade destes subprodutos em rações para peixes.

O presente estudo foi conduzido com o objetivo de avaliar o coeficiente de digestibilidade aparente dos nutrientes de rações para juvenis de tambaqui com níveis crescentes de substituição do milho pela farinha de crueira de mandioca.

\section{MATERIAL E MÉTODOS}

O experimento foi conduzido no Instituto Nacional de Pesquisas da Amazônia - INPA, Manaus-AM, na Coordenação de Pesquisas em Aquicultura CPAQ, no período de janeiro a fevereiro de 2009, totalizando 30 dias.

O delineamento experimental foi inteiramente casualizado, com seis tratamentos (dietas) e quatro repetições, perfazendo 24 unidades experimentais. Foram utilizados 336 juvenis de tambaqui com peso médio de $34,5 \pm 6,5$. Cada unidade experimental foi constituída por 14 juvenis de tambaqui alojados em um tanque com forma afunilada e capacidade para 300L, abastecido com água de poço artesiano, sistema de aeração artificial, renovação diária de água e sistema de funil na extremidade inferior para coleta das excretas.

As rações foram formuladas de modo a serem isoprotéicas (36\% PB) e isocalóricas (3500kcal ED/kg), com níveis crescentes $(0,20,40,60,80$ e $100 \%$ ) de substituição do milho por farinha de crueira de mandioca, correspondendo aos tratamentos controle, I, II, III, IV e V, respectivamente, (Tabela 1).

Para balanceamento das rações experimentais foi utilizado o programa Super Crac, desenvolvido pela Universidade Federal de Viçosa - UFV.

A crueira de mandioca utilizada no experimento foi obtida em casa de farinha artesanal. Por se tratar de um produto úmido ela foi desidratada em estufa a 60 graus Celsius, por 48 horas, sendo posteriormente moída em moinho tipo martelo, com matriz fina de $0,8 \mathrm{~mm}$. Para uniformização das 
PEREIRA JUNIOR, G. et al. Digestibilidade aparente de ração para tambaqui com níveis crescentes de substituição do milho por farinha de crueira de mandioca. PUBVET, Londrina, V. 8, N. 14, Ed. 263, Art. 1751, Julho, 2014.

partículas, todos os outros ingredientes utilizados na composição das rações passaram pelo mesmo processo de moagem.

Tabela 1 - Composição percentual dos ingredientes e características nutritivas das dietas experimentais com diferentes níveis de substituição do milho por farinha de crueira de mandioca (Manihot esculenta).

\begin{tabular}{|c|c|c|c|c|c|c|c|}
\hline \multirow{2}{*}{ Ingredientes } & \multicolumn{7}{|c|}{ Níveis de substituição da farinha de crueira (\%) } \\
\hline & 0 & 20 & \multirow{2}{*}{\multicolumn{2}{|c|}{$\begin{array}{c}40 \\
18,0\end{array}$}} & \multirow{2}{*}{$\begin{array}{c}60 \\
12,0\end{array}$} & \multirow{2}{*}{$\begin{array}{c}80 \\
6,0\end{array}$} & 100 \\
\hline Milho & 30,0 & 24,0 & & & & & 0,0 \\
\hline Farinha de crueira & 0,0 & 6,0 & \multicolumn{2}{|c|}{12,0} & 18,0 & 24,0 & 30,0 \\
\hline Óleo de soja & 3,6 & 3,7 & \multicolumn{2}{|c|}{3,4} & 3,6 & 3,2 & 3,6 \\
\hline Farelo de soja & 55 & 54 & \multicolumn{2}{|c|}{52,7} & 49,8 & 50,0 & 45,8 \\
\hline Farelo de glúten de milho & 2,0 & 2,0 & \multicolumn{2}{|c|}{3,6} & 7,0 & 7,0 & 10,0 \\
\hline Farinha de carne e ossos & 3,0 & 3,0 & \multicolumn{2}{|c|}{3,0} & 3,0 & 3,0 & 4,0 \\
\hline Farinha de peixe & 3,0 & 3,0 & \multicolumn{2}{|c|}{3,0} & 3,0 & 3,0 & 3,0 \\
\hline Fosfato bicálcico & 2,0 & 2,8 & \multicolumn{2}{|c|}{2,8} & 2,3 & 2,3 & 2,1 \\
\hline DL-metionina & 0,35 & 0,35 & \multicolumn{2}{|c|}{0,35} & 0,32 & 0,43 & 0,4 \\
\hline Premix & 1,0 & 1,0 & \multicolumn{2}{|c|}{1,0} & 1,0 & 1,0 & 1,0 \\
\hline Total & 100,0 & 100,0 & \multicolumn{2}{|c|}{$100,0 \quad 1$} & $00,0 \quad 10$ & 100,0 & 100,0 \\
\hline \multirow{2}{*}{ Nutrientes (\%) } & Níveis de & bstitui & ção c & a farin & inha de c & crueira & $(\%)$ \\
\hline & 0 & & 20 & 40 & 60 & 80 & 100 \\
\hline Matéria seca (\%) & 93,0 & & 4,2 & 93,5 & 93,5 & 94,1 & 94,2 \\
\hline Proteína bruta (\%) & 36,0 & & 6,0 & 36,0 & 36,0 & 36,0 & 36,0 \\
\hline Extrato etéreo (\%) & 3,6 & & 4 & 3,9 & 3,8 & 3,4 & 4,4 \\
\hline Cinzas (\%) & 7,3 & & 8 & 8,0 & 7,6 & 7,5 & 7,2 \\
\hline Fibra bruta (\%) & 1,8 & & 2 & 2,7 & 2,8 & 2,8 & 3,1 \\
\hline ENN (\%) & 42,0 & & 2,9 & 41,2 & 41,7 & 43,7 & 42,8 \\
\hline Energia bruta $(\mathrm{Kcal} / \mathrm{kg}) *$ & 4225 & & 225 & 4225 & 4225 & 4225 & 4225 \\
\hline EB: PB & 11,0 & & 1,0 & 11,0 & 11,0 & 11,0 & 11,0 \\
\hline
\end{tabular}

ENN = extrativo não nitrogenado; $\mathrm{EB}$ = energia bruta; $\mathrm{PB}=$ proteína bruta. *Calculado segundo NRC 1996. 
PEREIRA JUNIOR, G. et al. Digestibilidade aparente de ração para tambaqui com níveis crescentes de substituição do milho por farinha de crueira de mandioca. PUBVET, Londrina, V. 8, N. 14, Ed. 263, Art. 1751, Julho, 2014.

Para elaboração das rações, os ingredientes foram misturados com marcador inerte óxido de cromo $\left(\mathrm{Cr}_{2} \mathrm{O}_{3}\right)$, na proporção de 0,5\%, umedecidos e processados em moedor de carne, com matriz de $6 \mathrm{~mm}$, para a formação dos peletes. Para secagem destes, foi usada uma estufa com circulação forçada de ar, a temperatura constante de $60^{\circ} \mathrm{C}$, durante 48 horas. Após a elaboração das rações, foram coletadas amostras para determinação de suas composições centesimais, e o restante foi acondicionado em saco plástico e armazenado em freezer.

As análises químico-bromatológicas dos ingredientes e das rações foram determinadas segundo metodologia proposta pela AOAC (1997). O valor do extrato não-nitrogenado (ENN) foi calculado por diferença, segundo a fórmula $E E N=100-(U M+P B+E E+F B+C Z)$. A Energia bruta foi estimada com base nos valores calculados de energia para proteína $=5,64 \mathrm{Kcal} / \mathrm{g}$, extrato etéreo $=9,44 \mathrm{Kcal} / \mathrm{g}$ e extrato não-nitrogenado $=4,11 \mathrm{Kcal} / \mathrm{g}$ (NATIONAL RESEARCH COUNCIL, 1993).

Após distribuição aleatória dos juvenis de tambaqui nas unidades experimentais, houve um período de aclimatação de sete dias, onde os peixes receberam uma ração controle com 36\% de proteína bruta. Após este período, os animais ficaram em jejum durante 24 horas, depois foram alimentados com as rações experimentais ad libitum. O alimento foi fornecido três vezes ao dia, às 9:00, 13:00 e 17:30 horas.

$\mathrm{Na}$ porção inferior dos cones, junto a saída d'água, foi adaptado um sistema coletor de fezes constituído de juntas de PVC com registro hidráulico. A porção terminal do coletor possui uma rosca para encaixe de pré-formas de garrafa pet com volume de $50 \mathrm{~mL}$, para coleta das fezes. Foram colocadas telas metálicas em formato circular no interior dos cones, com malha de dez milímetros, separando uma área para permanência dos peixes e outra para decantação das fezes, evitando lixiviação excessiva do material.

As fezes foram coletadas por decantação na coluna da água, sendo efetuadas ao longo do dia, com início às 11 horas e término às 23 horas. Para 
PEREIRA JUNIOR, G. et al. Digestibilidade aparente de ração para tambaqui com níveis crescentes de substituição do milho por farinha de crueira de mandioca. PUBVET, Londrina, V. 8, N. 14, Ed. 263, Art. 1751, Julho, 2014.

evitar que os coeficientes de digestibilidade fossem subestimados, o registro do sistema de coleta de cada unidade experimental foi aberto para descarte dos peletes não consumidos, uma hora após a alimentação. Após o fechamento do registro, os tubos coletores foram encaixados, seguindo o intervalo de coleta de uma hora. As fezes decantadas nos tubos coletores foram retiradas, após o fechamento do registro, homogeneizadas e congeladas em placas de Petri para posterior liofilização e análises bromatológicas. A quantidade de material fecal necessária para realização das análises foi de dez gramas de peso seco. As análises da composição bromatológica das fezes, ingredientes e rações foram realizadas no Laboratório de Nutrição de Peixes/CPAQ/INPA.

As concentrações de óxido de cromo nas amostras de rações e fezes coletadas foram determinadas através do método colorimétrico, conforme metodologia descrita por Furukawa e Tsukahara (1966).

Foram determinados os coeficientes de digestibilidade aparente (CDA) da matéria seca, proteína bruta, fibra bruta, extrato não nitrogenado e extrato etéreo das rações. Para determinação do coeficiente de digestibilidade desses nutrientes foi aplicada a metodologia descrita por Cho et al. (1985).

$\mathrm{CDA}_{\text {MS }}=100 \times \mid 1-\left(\% \mathrm{Cr}_{2} \mathrm{O}_{3}\right.$ dieta $) /\left(\% \mathrm{Cr}_{2} \mathrm{O}_{3}\right.$ fezes $) \mid$

$\mathrm{CDA}_{\mathrm{n}}=100 \times 1-\left(\% \mathrm{Cr}_{2} \mathrm{O}_{3}\right.$ dieta $)\left(\% \mathrm{f}_{\mathrm{n} / \mathrm{e}}\right) /\left(\% \mathrm{Cr}_{2} \mathrm{O}_{3}\right.$ fezes $)(\% \mathrm{r} / \mathrm{e})$

Em que: $\mathrm{CDA}_{\mathrm{n}}=$ Coeficiente de digestibilidade aparente de nutrientes;

$\% \mathrm{Cr}_{2} \mathrm{O}_{3}$ dieta = \% de óxido de cromo na ração;

$\% \mathrm{Cr}_{2} \mathrm{O}_{3}$ fezes $=\%$ de óxido de cromo nas fezes;

$\% f_{n / e}=\%$ de nutriente nas fezes;

$\% r_{n / e}=\%$ de nutriente na ração.

A cada sete dias foram realizadas em todas as unidades experimentais, medidas de amônia, nitrito, gás carbônico, dureza e alcalinidade. Para estas determinações, foram utilizados o método da colorimetria (amônia e nitrito) e titulação (gás carbônico, dureza e alcalinidade). A cada dois dias foram 
PEREIRA JUNIOR, G. et al. Digestibilidade aparente de ração para tambaqui com níveis crescentes de substituição do milho por farinha de crueira de mandioca. PUBVET, Londrina, V. 8, N. 14, Ed. 263, Art. 1751, Julho, 2014.

aferidas as medidas de temperatura da água, $\mathrm{pH}$ e oxigênio dissolvido. Para determinar os valores de oxigênio dissolvido foi utilizado um oxímetro digital. As outras medidas foram verificadas com um peagâmetro digital. Estas medidas foram tomadas as 9:00 horas da manhã.

Para avaliar os efeitos dos tratamentos foi usada análise de variância (ANOVA) para os parâmetros físico-químicos da água: oxigênio, temperatura, $\mathrm{pH}$, dureza, alcalinidade e amônia. Por não terem atendido os pressupostos da ANOVA, foram submetidos ao teste de distribuição livre de Kruskal-Wallis $(p<0,05)$ os dados de parâmetros físico-químicos da água: gás carbônico e nitrito e digestibilidade aparente.

\section{RESULTADOS E DISCUSSÃO}

Os valores médios para as variáveis físico-químicas da água não apresentaram diferenças $(p>0,05)$ entre os tratamentos, conforme apresentado na Tabela 2 . Os valores observados estão dentro dos recomendados para o tambaqui (KUBITZA, 2003).

Dentre os parâmetros físico-químicos da água, o oxigênio dissolvido desempenha papel de destaque em estudos de digestibilidade in vivo. Níveis de oxigênio dissolvido abaixo da faixa ótima podem diminuir a capacidade de digestão e absorção de nutrientes pelos peixes (NÉJI; DE LA NOUE, 1998), o que provavelmente não ocorreu neste estudo, já que a concentração de oxigênio na água $(5,8 \pm 0,3$ a 6,1 $\pm 0,3)$ manteve-se acima de $3,0 \mathrm{mg} / \mathrm{L}$, que é o limite crítico inferior para o tambaqui (KUBITZA, 2003).

Não foram observadas diferenças significativas $(p \geq 0,05)$ entre os tratamentos para o coeficiente de digestibilidade aparente da matéria seca, do extrato etéreo, da proteína bruta e do extrato não nitrogenado, conforme apresentado na Tabela 3. 
PEREIRA JUNIOR, G. et al. Digestibilidade aparente de ração para tambaqui com níveis crescentes de substituição do milho por farinha de crueira de mandioca. PUBVET, Londrina, V. 8, N. 14, Ed. 263, Art. 1751, Julho, 2014.

Tabela 2 - Parâmetros físico-químicos da água, durante o período experimental (média e desvio padrão).

\section{Tratamento}

Parâmetro (\% de substituição do milho por farinha de crueira de mandioca)

\begin{tabular}{|c|c|c|c|c|c|c|}
\hline & $\begin{array}{c}\text { Controle } \\
(0 \%)\end{array}$ & $\begin{array}{c}\text { TI } \\
(20 \%)\end{array}$ & $\begin{array}{c}\text { TII } \\
(40 \%)\end{array}$ & $\begin{array}{c}\text { TIII } \\
(60 \%)\end{array}$ & $\begin{array}{c}\text { TIV } \\
(80 \%)\end{array}$ & $\begin{array}{c}\text { TV } \\
(100 \%)\end{array}$ \\
\hline $\begin{array}{ll}\mathrm{O}_{2} & \text { diss. } \\
(\mathrm{mg} / \mathrm{L}) & \end{array}$ & $5,8 \pm 0,3$ & $5,9 \pm 0,3$ & $6,0 \pm 0,2$ & $6,1 \pm 0,3$ & $5,9 \pm 0,2$ & $6,0 \pm 0,2$ \\
\hline $\begin{array}{l}\text { Temperat. } \\
\left({ }^{\circ} \mathrm{C}\right)\end{array}$ & $26,7 \pm 0,3$ & $26,6 \pm 0,4$ & $27,0 \pm 0,3$ & $27,0 \pm 0,3$ & $27,4 \pm 0,2$ & $27,4 \pm 0,2$ \\
\hline $\mathrm{pH}$ & $5,5 \pm 0,4$ & $5,6 \pm 0,1$ & $5,6 \pm 0,2$ & $5,5 \pm 0,1$ & $5,6 \pm 0,1$ & $5,5 \pm 0,1$ \\
\hline $\begin{array}{l}{\left[\mathrm{NH}_{3}\right]_{\text {total }}} \\
(\mathrm{mg} / \mathrm{L})\end{array}$ & $0,5 \pm 0,1$ & $0,5 \pm 0,2$ & $0,5 \pm 0,1$ & $0,6 \pm 0,1$ & $0,6 \pm 0,3$ & $0,3 \pm 0,1$ \\
\hline $\mathrm{NO}_{2}^{-}(\mathrm{mg} / \mathrm{L})$ & $0,02 \pm 0,1$ & $0,02 \pm 0,0$ & $0,02 \pm 0,1$ & $0,02 \pm 0,0$ & $0,02 \pm 0,0$ & $0,02 \pm 0,1$ \\
\hline $\begin{array}{l}\text { Dureza } \\
\text { (mg/L) }\end{array}$ & $2,0 \pm 0,3$ & $2,2 \pm 0,3$ & $2,1 \pm 0,3$ & $2,0 \pm 0,2$ & $2,0 \pm 0,0$ & $2,0 \pm 0,1$ \\
\hline $\begin{array}{l}\text { Alcalin. } \\
\text { (mg/L) }\end{array}$ & $2,1 \pm 0,2$ & $2,3 \pm 0,2$ & $2,3 \pm 0,2$ & $2,5 \pm 0,1$ & $2,3 \pm 0,2$ & $2,0 \pm 0,3$ \\
\hline $\mathrm{CO}_{2}(\mathrm{mg} / \mathrm{L})$ & $11,1 \pm 0,3$ & $11,0 \pm 0,2$ & $12,2 \pm 0,2$ & $11,0 \pm 0,3$ & $12,0 \pm 0,1$ & $12,1 \pm 0,1$ \\
\hline
\end{tabular}

Tabela 3 - Coeficiente de digestibilidade aparente (CDA) dos nutrientes das rações contendo níveis crescentes de substituição do milho pela farinha de crueira de mandioca (média e desvio padrão).

\begin{tabular}{lcclcc}
\hline \multirow{2}{*}{ Tratamento } & \multirow{2}{*}{ Crueira } & \multicolumn{4}{c}{ CDA (\%) dos nutrientes das rações } \\
\cline { 2 - 6 } & & CDA ms & CDA ee & CDA prot. & CDA enn \\
\hline Controle & $0 \%$ & $72,0 \pm 1,0$ & $95,0 \pm 2,0$ & $90,0 \pm 2,0$ & $55,0 \pm 1,0$ \\
TI & $20 \%$ & $69,0 \pm 3,0$ & $96,0 \pm 1,0$ & $89,0 \pm 1,0$ & $53,0 \pm 4,0$ \\
TII & $40 \%$ & $69,0 \pm 3,0$ & $89,0 \pm 4,0$ & $89,0 \pm 3,0$ & $51,0 \pm 1,3$ \\
TIII & $60 \%$ & $77,0 \pm 0,0$ & $93,0 \pm 1,0$ & $90,0 \pm 0,0$ & $67,0 \pm 1,0$ \\
TIV & $80 \%$ & $75,0 \pm 2,0$ & $95,0 \pm 3,0$ & $89,0 \pm 2,0$ & $64,0 \pm 3,0$ \\
TV & $100 \%$ & $76,0 \pm 2,0$ & $90,0 \pm 6,0$ & $88,0 \pm 3,0$ & $67,0 \pm 3,0$ \\
\hline MS = matéria seca; ee = extrato etéreo; prot. Proteína; enn = extrato não nitrogenado.
\end{tabular}


PEREIRA JUNIOR, G. et al. Digestibilidade aparente de ração para tambaqui com níveis crescentes de substituição do milho por farinha de crueira de mandioca. PUBVET, Londrina, V. 8, N. 14, Ed. 263, Art. 1751, Julho, 2014.

Os valores de digestibilidade total encontrados neste trabalho $(69,0 \pm 3,0$ a $77,0 \pm 0,0$ ) sugerem que o tambaqui é capaz de aproveitar bem os nutrientes das rações, independente se a principal fonte energética é o milho ou a farinha de crueira de mandioca. Isso comprova a capacidade que esta espécie possui em aproveitar bem alimentos de origem vegetal ricos em amido (ARAÚJO-LIMA; GOULDING, 1998), a exemplo da crueira de mandioca que é composta basicamente por carboidrato.

Esta capacidade pode estar relacionada com adaptações morfológicas do aparelho digestivo do tambaqui, já que existe após o estômago um grande número de projeções denominadas cecos pilóricos seguidos de um longo intestino (SAINT-PAUL, 1984). Um peixe adulto pode ter até 75 cecos pilóricos, ou apêndices ligados ao estômago. Acredita-se que este grande número de cecos ajude na digestão de material vegetal. O comprimento do intestino no tambaqui adulto alcança em média cerca de 5,5 a 6 vezes o comprimento do corpo. Isto é similar a muitas espécies de peixes detritívoros e herbívoros (ARAÚJO-LIMA; GOULDING 1998). Diferentes estudos apontam para a capacidade que o tambaqui possui em utilizar bem alimentos de origem vegetal em dietas artificiais (KOHLA et al., 1992; ROUBACH; SAINT-PAUL, 1994; SILVA et al., 2003; LEMOS et al., 2011).

Apesar de não ter havido diferenças significativas entre os tratamentos, os maiores valores numéricos para digestibilidade total foram observados nas rações do tratamento III, IV e $V(77,0 \pm 0,0,75,0 \pm 2,0$ e 76,0 $\pm 2,0$, respectivamente). Já os menores valores foram observados nos tratamentos I, II $(69 \pm 3,0)$ e controle $(72,0 \pm 1,0)$. Esses resultados indicam que o tambaqui apresentou maior eficiência digestiva para as rações com maiores níveis de substituição do milho pela farinha de crueira de mandioca. Isso provavelmente está relacionado com os maiores valores para o coeficiente de digestibilidade aparente do extrato não nitrogenado, observados nos tratamentos III, IV e V $(67,0 \pm 1,0,64,0 \pm 3,0$ e 67,0 $\pm 3,0$, respectivamente), já que os coeficientes de digestibilidade aparente da proteína bruta e do extrato etéreo apresentaram 
PEREIRA JUNIOR, G. et al. Digestibilidade aparente de ração para tambaqui com níveis crescentes de substituição do milho por farinha de crueira de mandioca. PUBVET, Londrina, V. 8, N. 14, Ed. 263, Art. 1751, Julho, 2014.

valores numéricos muito próximos entre os tratamentos, conforme apresentado na Tabela 3.

Os resultados encontrados nesta pesquisa, para a variável digestibilidade aparente da matéria seca, concordam com Campeche et al. (2011) que avaliaram o coeficiente de digestibilidade da raspa de mandioca para tilápia rosa (Oreochromis sp.) e concluíram que este ingrediente pode ser utilizado em rações para esta espécie de peixe. Segundo eles, o hábito alimentar onívoro da tilápia rosa pode ter contribuído para o coeficiente de digestibilidade observado. Concordam, ainda, com Cantelmo et al. (2002) que determinaram a influência de vários aglutinantes: carboximetilcelulose, polimetilcarbamida, amido de mandioca, alginato de sódio, polivinilpirrolidona e goma guar, bem como a técnica de processamento, com e sem vapor, na digestibilidade aparente das frações matéria seca e proteína bruta para o pacu (Piaractus mesopotamicus). Estes autores verificaram que a gelatinização do amido de mandioca proporcionou bons resultados para digestibilidade aparente das rações. Entretanto, discordam de Santos et al. (2009) que estudaram a digestibilidade da matéria seca da farinha de casca de mandioca para tilápia do Nilo (Oreochromis niloticus). Estes autores observaram baixos índices de digestibilidade para este ingrediente, concluindo que os elevados conteúdos de polissacarídeos não amiláceos e de fibra bruta presentes na casca podem ter dificultado a digestibilidade.

Durante a fabricação da farinha de mandioca, a raiz desta planta é submersa em água por aproximadamente três dias, ocorrendo fermentação. Esta é uma prática comum na fabricação de farinha na região amazônica e, segundo os produtores de farinha, está relacionada com o sabor do produto final. Esta fermentação pode ter contribuído para facilitar a digestão da farinha de crueira de mandioca pelo tambaqui, já que os microorganismos podem ter desestruturado as moléculas de amido, favorecendo a absorção da glicose a nível intestinal (HEPHER, 1993). Isso pode explicar os maiores valores observados nesta pesquisa para o coeficiente de digestibilidade aparente do extrato não nitrogenado dos tratamentos III, IV e V $(67,0 \pm 1,0,64,0 \pm 3,0$ e 
PEREIRA JUNIOR, G. et al. Digestibilidade aparente de ração para tambaqui com níveis crescentes de substituição do milho por farinha de crueira de mandioca. PUBVET, Londrina, V. 8, N. 14, Ed. 263, Art. 1751, Julho, 2014.

$67,0 \pm 3,0$, respectivamente), quando comparados aos tratamentos controle, I e II $(55,0 \pm 1,0,53,0 \pm 4,0,51,0 \pm 1,3$, respectivamente $)$.

O efeito da fermentação microbiana sobre a desestruturação das moléculas de amido também foi reportado por Silva et al. (2005) ao estudarem a composição bromatológica e digestibilidade in vitro da matéria seca de silagens de milho e de sorgo tratados com inoculantes microbianos. Estes autores observaram que a utilização destes inoculantes nas silagens ricas em grãos proporcionaram aumento na solubilidade dos carboidratos, aumentando da digestibilidade da matéria seca e, portanto, o valor nutritivo potencial. Resultado semelhante também foi observado por Mendes et al. (2008) ao inocularem Lactobacillus buchneri em silagem de cana-de-açúcar.

Os resultados encontrados nesta pesquisa para a variável digestibilidade aparente de carboidratos concordam com o trabalho de Boscolo et al. (2002), que encontraram valores altos para esta variável em vários ingredientes, incluindo farinha de varredura de mandioca, para tilápia do Nilo (Oreochromis niloticus). Concluíram que a tilápia utiliza de forma eficiente os carboidratos da dieta, sendo esta característica desejável, visto que geralmente os alimentos ricos em amido são fontes de energia de menor custo.

O coeficiente de digestibilidade aparente da proteína bruta apresentou valores muito próximos entre os tratamentos, sendo o maior valor numérico observado nos tratamentos controle e III $(90,0 \pm 2,0)$ e o menor no tratamento $V(88,0 \pm 3,0)$. Estes valores são superiores aos observados por Santos et al. (2009) que estudaram a digestibilidade de subprodutos da mandioca para a tilápia do Nilo (Oreochromis niloticus). E são muito próximos aos observados por Pezzato et al. (2004) que utilizaram 67,39\% de inclusão de raspa de mandioca na ração teste para juvenis de tilápia.

Os resultados encontrados neste trabalho demonstram a elevada capacidade do tambaqui em utilizar eficientemente a farinha de crueira de mandioca como ingrediente em rações. Sendo assim, este ingrediente por apresentar um custo de obtenção inferior aos ingredientes convencionalmente utilizados em rações para peixes pode ser considerado alimento promissor para 
PEREIRA JUNIOR, G. et al. Digestibilidade aparente de ração para tambaqui com níveis crescentes de substituição do milho por farinha de crueira de mandioca. PUBVET, Londrina, V. 8, N. 14, Ed. 263, Art. 1751, Julho, 2014.

o tambaqui. Novos estudos são necessários para avaliar o uso deste ingrediente em rações para outras espécies de peixes nativos.

\section{CONCLUSÃO}

A substituição total do milho pela farinha de crueira de mandioca em rações para juvenis de tambaqui não compromete a digestibilidade aparente dos nutrientes.

\section{Agradecimentos}

A Fundação de Amparo à Pesquisa do Estado do Amazonas - FAPEAM pela bolsa de estudos e suporte financeiro para execução do projeto. Ao Programa de Pós-Graduação em Biotecnologia da Universidade Federal do Amazonas UFAM pela oportunidade. Ao Instituto Nacional de Pesquisas da Amazônia INPA pelo auxílio estrutural. A Larissa Gonçalves Rangel pela tradução do resumo.

\section{REFERÊNCIAS}

ABMORAD, E. G.; CARNEIRO, D. J. Métodos de coleta de fezes e determinação dos coeficientes de digestibilidade da fração protéica e da energia de alimentos para o pacu Piaractus mesopotamicus (Holmberg, 1887). Rev. Bras. de Zootec., v. 33, p. 1101-1109, 2004.

ABRAHÃO, J. J. S.; PRADO, I. N.; PEROTTO, D.; ZEOULA, L. M.; LANÇANOVA, J. A. C.; LUGÃO, S. M. B. Digestibilidade de dietas contendo resíduo úmido de mandioca em substituição ao milho para tourinhos em terminação. Rev. Bras. de Zootec., v. 35, p. 1447-1453, 2006.

A.O.A.C. Official Methods of Analysis. 17th. Ed. Gaithersburg, USA: Association of Official Analytical Chemists Int. 1997.

ARAÚJO-LIMA, C.; GOULDING, M. Os frutos do tambaqui: ecologia, conservação e cultivo na Amazônia. Tefé, AM: Sociedade Civil Mamirauá/CNPq. 1998. 187 pp.

ARBELAEZ-ROJAS, G. A.; FRACALOSSI, D. M.; FIM, J. D. I. Composição corporal de tambaqui, Colossoma macropomum, e matrinxã, Brycon cephalus, em sistemas de cultivo intensivo, em igarapé, e semi-intensivo, em viveiros. Rev. Bras. de Zootec., v. 31, p. 1059-1069, 2002. 
BOSCOLO, W.; HAYASHI, C.; MEURER, F. Digestibilidade aparente da energia e nutrientes de alimentos convencionais e alternativos para tilápia do Nilo (Oreochromis niloticus). Rev. Bras. de Zootec., v. 31, p. 1-9, 2002.

Campeche, D. F. B.; Moraes, S. A.; Lima, V. T.; Sousa, S. M. N.; Oliveira, S. T. L.; Sousa, M. G.; Paulino, R. V. Composição bromatológica e digestibilidade aparente de alimentos encontrados na região semiárida brasileira para arraçoamento de tilápia rosa em cultivos. Ciênc. Rur., v. 41, p. 343-348, 2011.

CANTELMO, A. O.; PEZZATO, E. L.; BARROS, M. M.; PEZZATO, A. C. Características físicas de dietas para peixes confeccionadas com diferentes aglutinantes. Acta Scient., v. 24, p. 949955, 2002.

CAVALCANTE, R. R.; FIGUEIREDO, A. V.; CARVALHO, M. A. M.; LOPES, J. B.; ALMEIDA, M. M. Digestibilidade aparente de nutrientes de rações balanceadas com alimentos alternativos para cutias (Dasyprocta prymnolopha) em crescimento. Ciênc. Anim. Bras., v. 6, p. 163-171, 2005.

CEREDA, M. P. Caracterização dos resíduos da industrialização da mandioca, p. 11-50. In: Cereda, M. P. (Eds). Resíduos da industrialização da mandioca. São Paulo. 1994.

CHENG, Z. J.; HARDY, R. W.; USRY, J. L. Effects of lysine supplementation in plant proteinbased diets on the performance of rainbow trout Oncorhynchus mykiss and apparent digestibility coefficients of nutrients. Aquaculture, v. 215, p. 255-265, 2003.

CHO, C. Y.; COWEY, C. B.; WATANABE, T. Finfish nutrition in Asia: methodological approaches to research and development. Otawa: IDRC. 1985. 154 p.

Furukawa, A.; Tsukahara, H. On the acid digestion method for the determination of chromic oxide as an index in the study of digestibility of fish feed. Bull of the Jap. Soc. Scien. Fisheries, v. 32, p. 502-506, 1966.

GALDIOLI, E. M.; HAYASHI, C.; SOARES, C. M.; FURUYA, V. R. B.; FARIA, A. C. A. Substituição da Proteína do Farelo de Soja pela Proteína do Farelo de Canola em Rações para Alevinos de Curimbatá (Prochilodus lineatus). Rev. Bras. de Zootec., v. 31, p. 552-559, 2002.

GRAEF, E. W. As espécies de peixes com potencial para criação no Amazonas. In: VAL, L. A.; HONCZARK, A. (Eds). p. 29-43. Criando peixes na Amazônia. Instituto Nacional de Pesquisas da Amazônia, Manaus, Amazonas. 1995.

GuimarÃEs, I. G.; PEZZATO, L. E.; BARROS, M. M.; TACHIBANA, L.; FERNANDES, R. N. Digestibilidade do amido e disponibilidade de $\mathrm{Ca}$ e $\mathrm{P}$ em alimentos energéticos extrusados para a tilápia do Nilo (Oreochromis niloticus). Ciênc. Anim. Bras., v. 12, p. 415-419, 2011.

HANCZ, C. Performance of the Amazonian tambaqui, Colossoma macropomum, in pond polyculture. Aquaculture, v. 12: p. 245-254, 1993.

HEPHER, B. 1993. Nutrición de peces comerciales em estanques. México: Limusa. 406 pp.

KOHLA, U.; SAINT-PAUL, U.; FRIEBE, J.; WERNICKE, D.; HILBE, V.; BRAUM, E.; GROPP, J. Growth, digestive enzyme activities and hepatic glycogen leavels in juvenile Colossoma macropomum Cuvier from South America during feeding, starvation and refeeding. Aquac. Fish. Manag., v. 23, p. 189-208, 1992. 
KUBITZA, F. Qualidade da água no cultivo de peixes e camarões. Jundiaí. SP: Jundiaí. 2003. 229 p.

LACERDA, C. H. F.; HAYASHI, C.; SOARES, C. M.; BOSCOLO, W. R.; KAVATA, L. C. B. Farelo de mandioca (Manihot esculenta) em substituição ao milho (Zea mays) em rações para alevinos de carpa capim (Ctenopharyngodon idella). Act. Scient., v. 27, p. 241-245, 2005.

LEMOS, M. V. A.; GUIMARÃES, I. G.; MIRANDA, E. D. Farelo de coco em dietas para tambaqui (Colossoma macropomum). Rev. Bras. Saúde Prod. Anim., v. 12, p. 188-198, 2011.

LOPES, J. M.; PASCOAL, L. A. F.; SILVA FILHO, F. P.; SANTOS, I. B.; WATANABE, P. H.; ARAÚJO, D. M.; PINTO, D. C.; OLIVEIRA, P. S. Farelo de babaçu em dietas para tambaqui. Rev. Bras. Saúde Prod. Anim., v. 11, p. 519-526, 2010.

MENDES, C. Q.; SUSIN, I.; NUSSIO, L. G.; PIRES, A. V.; RODRIGUES, G. H.; URANO, F. S. Efeito do Lactobacillus buchneri na fermentação, estabilidade aeróbia e no valor nutritivo de silagem de cana-de-açúcar. Rev. Bras. de Zootec., v. 37, p. 2191-2198, 2008.

MENEZES, M. P. C.; RIBEIRO, M. N.; COSTA, R. G.; MEDEIROS, A. S. N. Substituição do milho pela casca de mandioca (Manihot esculenta) em rações completas para caprinos: consumo, digestibilidade de nutrientes e ganho de peso. Rev. Bras. de Zootec., v. 33 p. 1-11; 2004.

MEURER, F.; HAYASHI, C.; BOSCOLO, W. R. Digestibilidade aparente de alguns alimentos protéicos pela tilápia do Nilo (Oreochromis niloticus). Rev. Bras. de Zootec., v. 32, p. 18011809, 2003.

NASCIMENTO, G. A. J.; COSTA, F. G. P.; AMARANTE-JÚNOR, V. S.; BARROS, L. R. Efeitos da substitutição do milho pela raspa da mandioca na alimentação de frangos de corte, durante as fases de engorda e final. Rev. Ciênc. Agrotéc., v. 29, p. 200-207, 2005.

NATIONAL RESEARCH COUNCIL - NRC. Nutrients requirements of warmwater fishes and shellfishes. Washington: Academy Press. 1993. 102 pp.

NÉJI, H.; DE LA NOUE, J. Effect of animal and vegetal protein diets on feed intake and apparent digestibility of nutrients in rainbow trout (Oncorhynchus mykiss) infected by Aeromonas salmonicida, with and without chronic hipoxia stress. Canad. J. Fish. Aquat. Sci., v. 55, p. 2019-2027, 1998.

OLIVEIRA-FILHO, P. R. C.; FRACALOSSI, D. M. Coeficientes de digestibilidade aparente de ingredientes para juvenis de jundiá. Rev. Bras. de Zootec., v. 35, p. 1581-1587, 2006.

ONO, E. A.; NUNES, E. S. S.; CEDANO, J. C. C.; PEREIRA-FILHO, M.; ROUBACH, R. Digestibilidade aparente de dietas práticas com diferentes relações energia:proteína em juvenis de pirarucu. Pesq. Agropec. Bras., v. 43, p. 249-254, 2008.

PEREIRA-FILHO, M. Alternativas para a alimentação de peixes em cativeiro. In: VAL, L. A.; HONCZARK, A. (Eds). p. 75-82. Criando peixes na Amazônia. Instituto Nacional de Pesquisas da Amazônia, Manaus, Amazonas. 1995.

PEZZATO, L. E.; MIRANDA, E. C.; BARROS, M. M.; PINTO, L. G. Q.; FURUYA, W. M.; PEZZATO, A. C. Digestibilidade aparente de ingredientes pela tilapia do Nilo (Oreochromis niloticus). Rev. Bras. de Zootec., v. 31, p. 1595-1604, 2002. 
PEZZATO, L. E.; MIRANDA, E. C.; BARROS, M. M.; PINTO, L. G. Q.; FURUYA, W. Digestibilidade aparente da matéria seca e da proteína e a energia digestível de alguns alimentos alternativos pela tilápia do Nilo (O. niloticus). Acta Sci., v. 26, p. 329-337, 2004.

PEZZATO, L. E.; BARROS, M. M.; FURUYA, W. M. Valor nutritivo dos alimentos utilizados na formulação de rações para peixes tropicais. Rev. Bras. de Zootec., v. 38, p. 43-51, 2009.

PIMENTA, C. J.; OLIVEIRA, M. M.; FERREIRA, L. O. PIMENTA, M. E. S. G.; LOGATO, P. V. R.; LEAL, R. S.; MURGAS, L. D. S. Aproveitamento de resíduo do café na alimentação de tilápia do Nilo. Arch. Zootec., v. 60, p. 583-593, 2011.

RAMOS, P. R.; PRATES, E. R.; FONTANELLI, R. S.; BARCELOS, J. O. J.; LANGWINSK, D.; BONELLI, I. B. Uso de bagaço de mandioca em substituição ao milho no concentrado para bovinos em crescimento: Digestibilidade aparente, consumo de nutrientes digestíveis, ganho de peso e conversão alimentar. Rev. Bras. de Zootec., v. 29, p. 300-305, 2000.

ROLIM, P. R. A infra-estrutura básica para criação de peixes no Amazonas. In: VAL, L. A.; HONCZARK, A. (Eds). p. 7-16. Criando peixes na Amazônia. Instituto Nacional de Pesquisas da Amazônia, Manaus, Amazonas. 1995.

ROUBACH, R.; SAINT-PAUL, U. Use fruits and seeds from Amazonian inundated forest in feeding trials with Colossoma macropomum (Cuvier, 1818) (Pisces, Characidae). J. Appl. Ichth., v. 101, p. 34-140, 1994.

RUfFINO, M. L. Estatística pesqueira do Amazonas e Pará. Ibama; ProVárzea. 2002. 73 p.

SAINT-PAUL, U. Ecological and physiological investigations of Colossoma macropomum, a new species for fish culture in Amazonia. Mem. la Assoc. Latin. Acuic., v. 5, p. 501-518, 1984.

SANTOS, E. L.; LUDKE, M. C. M.; RAMOS, A. M. P.; BARBOSA, J. M.; LUDKE, J. V.; RABELLO, C. B. V. Digestibilidade de subprodutos da mandioca para tilápia do Nilo. Rev. Bras. de Ciênc. Agr., v. 4, p. 358-362, 2009.

SILVA, P. C.; MESQUITA, A. J.; PALMA, C. S.; OLIVEIRA, A. N. Aspectos biométricos, bacteriológicos e físico-químicos do tambaqui (Colossoma macropomum) criado em consórcio com suínos. Rev. Bras. de Zootec., v. 5, p. 6-8, 1991.

SILVA, J. A. M.; PEREIRA-FILHO, M.; OLIVEIRA-PEREIRA, M. I. Frutos e sementes consumidos pelo tambaqui, Colossoma macropomum (Cuvier, 1818) incorporados em rações. Digestibilidade e velocidade de transito pelo trato gastrointestinal. Rev. Bras. de Zootec., v. 32, p. 2-12, 2003.

SILVA, V. S.; PEREIRA, O. G.; GARCIA, R.; VALADARES-FILHO, S. C.; CECON, P. R.; FERREIRA, C. L. L. F. Composição bromatológica e digestibilidade in vitro da matéria seca de silagens de milho e sorgo tratados com inoculantes microbianos. Rev. Bras. de Zootec., v. 34, p. 1881-1890, 2005.

SILVA, J. A. M.; PEREIRA-FILHO, M.; CAVERO, B. A. S.; OLIVEIRA-PEREIRA, M. I. Digestibilidade aparente dos nutrientes e energia de ração suplementada com enzimas digestíveis exógenas para juvenis de tambaqui (Colossoma macropomum CUVIER, 1818). Acta Amaz., v. 37, p. 157-164, 2007.

SILVA, M. A. A.; FURLAN, A. C.; MOREIRA, I.; PAIANO, D.; SCHERER, C.; MARTINS, E. N. Avaliação nutricional da silagem de raiz de mandioca contendo soja integral para leitões na fase inicial. Rev. Bras. de Zootec., v. 37, p. 1441-1449, 2008. 
TAGLIARI, P. S. Agro-indústria de mandioca de mandioca: desafios para os pequenos empresários. Agropec. Catarinense, v. 9, p. 37-42, 1996.

VAL, A. L. A criação de peixes na Amazônia: um futuro promissor. In: VAL, L. A.; HONCZARK, A. (Eds). p. 1-5. Criando peixes na Amazônia. Instituto Nacional de Pesquisas da Amazônia, Manaus, Amazonas. 1995.

VAL, A. L.; SILVA, M. N. P.; ALMEIDA-VAL, V. M. F. Hypoxia adaptation in fish of the Amazon: a never-ending task. South Afr. J. Zool., v. 33, p. 107-114, 1998. 